\title{
The Construction Project PPP Risk Distribution Study
}

\author{
Yang Chenhui
}

Sichuan vocational and technical college of communications.611130

\section{Key words: Construction project; The PPP risk; Distribution study}

\begin{abstract}
In recent years, the development trend of global economic integration to strengthen gradually, our country social economy obtained the development which progresses by leaps and bounds and the construction of infrastructure in the areas of demand is also growing. With the significant increase of investment, which makes the government in finance can withstand the pressure is more and more big. At the same time, many private enterprises gradually realize the importance of building infrastructure. In order to ensure the effective of government financial pressure relief, gradually increased the investment in terms of money. The PPP mode, as a kind of new model dominated by the government, the enterprise and the government has been vigorously promoted and widely used before. At the same time of revenue sharing, achieve the reasonable allocation of risk, and under the guidance of the principles of equality, justice and fairness, a smooth gradually built up a good communication platform, to achieve reasonable allocation of risk.
\end{abstract}

\section{Introduction}

The so-called PPP mode is under the leading role of the government and enterprises to establish a new type of partnership. From the perspective of construction management, the PPP is the main way to effective project management. From the perspective of practice, the construction of related parts gradually by the government in the field of project by way of franchising to manage social unit, unit in a certain extent by the government and the society to share the whole process of risk, also shared interests. So establishing and perfecting the risk allocation mechanism is very necessary.

\section{The salient feature of the PPP mode}

In the process of construction of the whole project, the relevant managers for the realization of unity and coordination of the parties to the construction unit, ensure the smooth progress of the overall project, tend to create a trusted parties of organizational culture. And by means of the open platform, will the parties responsibilities clear and clear division of labor, and between the parties work can achieve good cohesion on the platform, for each join the individual provide good project efficient channels of communication and exchanges. At the same time, to ensure that the engineering products of high quality and bring cooperated-builing parties expected even than expected earnings in the very great degree is the important purpose of project construction. The PPP mode in order to win-win cooperation is the main idea, through efficient allocation of risks and benefits to maximize the implementation of the economic and social benefit maximization. It can be said to be a kind of built on partnerships and flexible characteristics are very obvious cultural organization. By comparing the other project management model, can be its own remarkable characteristics, summarized below:

First, under certain conditions, the PPP mode can close contact of numerous construction projects, for the whole team in the project construction in the process of establishing a common goal. Then under the guidance of this goal, each cooperated-builing just can carry on the comprehensive consideration to the project as a whole and to work together and mutual trust between each other, contribute own strength for the construction of joint projects. At the same time, timely communication, efficient sharing of resources, a clear division of responsibilities, clear responsibilities and risk pooling is the basic guiding thought of this model.

Second, perfect communication and coordination mechanism is very important to the PPP mode. Based on cooperated-builing parties in the project construction of the same goals, is not a 
competitive relationship between each other but a good partnership. So under the guidance of good communication and coordination mechanism, a pr team with superb technology to build. No matter how much technical problems encountered in the process of project construction, rely on the force of the team can be solved to some extent, and can strengthen the communication and exchanges the cooperated-builing parties, thus helps to ensure that project smoothly.

Third, the cooperated-builing parties in the PPP mode, signed agreement, the relation between the partners to each other are corresponding to a certain commitment, and under the demand of the construction of the project, jointly set up a good team.It is advantageous to the effective sharing of various materials in the team to create a good working environment. At the same time, in the specific management, through the incentive constraints mechanism of use can be effectively improved in the aspect of risk management, and maintain the interests of all parties in the quality, progress and cost between the balanced development, in order to ensure that all parties can maximize realizing the maximization of economic and social benefits.

Fourth, maximum limit to ensure the maximization of their own economic interests, can be said to be each party joining into the common pursuit in the project construction. In the PPP mode, the cooperated-builing parties will inevitably be mutual constraints and constraints. But in this mode can be very good to share risks in engineering construction process, the phenomenon of the problem and the cooperated-builing parties each other can get effective avoid to a certain extent, and the ability to ensure project to be able to ensure the quality of within the prescribed time to complete the task, the maximum to avoid resource waste in the process of construction, strengthen the partnership between the cooperated-builing parties.

\section{The concrete classification of the construction project risk}

Depending on the Angle and the reference standard, the classification of the construction project risk has significant difference.

First, according to the different sources of risk factors, it can be divided into natural and man-made risks.

Second, according to the can achieve effective control, the risk of construction project can be divided into system and risk control. Risk of so-called system is mainly in the project can be reasonably control within the effective range of the various risks, such as market, interest rates and a normal laws and regulations, etc.

Third, according to the specific order of the normal operation of the PPP mode, the risk of construction project itself can be divided into financing, construction, operation and bidding risk.

Fourth, according to the size of the risk of specific scope, project risk can be divided into two kinds, namely the global and local risk.

\section{The PPP model can apply to specific circumstances}

First, the owner of the project construction is relatively more, had better be that kind of a long-term investment, and the project of the case owner party cooperated-builing parties closer ties and mutual trust between each other. At the same time, cooperate with cooperated-builing carlson number is more, can also be comprehensive and accurate grasp the situation of the parties, such as cooperated-builing parties itself at the use of technology, equipment, etc., which helps the owner to screening for many cooperated-builing choose various conditions are better the project project owner, and establish a long-term cooperative partnership. This for each project and the effect of construction is signed a partnership to many, not only can greatly save the time spent looking for partners need, but also the project of trust between each other, more assured quality of the construction of the project.

Second, the special project bidding, especially those who are not suitable for open tender project, or it is the only secret by inviting bidding project. However, based on the particularity of the project itself, the consortium's credibility is relatively much higher. With the high-speed development of our social economy, the need for some key projects strict and effective control of the important 
content, such as some construction projects related to the national security secrets, then need to strict screening of partners. The enterprise prestige is good or not is an important selection standard, and the stand or fall of first cooperation, to a certain extent, is directly related to the future long-term cooperative partnership.

Third, some technical requirements for higher, difficulty is big and there are many risks. Each cooperated-builing parties need to strengthen the exchange and communication between each other to jointly conquer technology on a variety of difficulties, in order to ensure the smooth progress of project construction. At the same time, based on some of the complexity of the project itself, many uncertainty factors, in this case the cooperated-builing parties between the contradictions and disputes. But the good cooperation partnership can effective to scientific processing of these contradictions and disputes, in order to help in reducing the economic cost in the process of construction projects to promote common goals.

Fourth, transnational and international financial institutions loans. For international project, at the request of the technical aspects will be very expensive, and are often public bidding way. Some project construction mainly rely on loans, making the cooperated-builing parties in the controversy over construction costs never interrupt and lurking in the direction of the wind in the contract will also increase accordingly. Partners, however, the PPP mode has very rich experience in international project construction, in view of the problems in the construction of the project to be able to take effective measures in the first good solution.

\section{Conclusion}

In recent years, with the rapid development of social economy and the increasingly progress of era, quickening the urbanization process, makes the construction of various infrastructure projects in the city has made great progress than before, and have great changes have taken place in both quantity and scale. At the same time, based on the construction of infrastructure projects in time and space of extensibility is more special, which makes the uncontrollable factors in the construction of the whole project not only complicated but also change very fast, resulting in the project construction has a great deal of risk coefficient. The PPP mode, however, as a new kind of mode, the application of it makes originally the cooperated-builing parties affiliations, great changes have taken place in implements to strengthen risk control and scientific management, and finally help to achieve the goal of construction of common, help the parties to the maximum economic and social benefits.

\section{References}

[1] $\mathrm{Hu}$ Yueliang. Try to talk about construction enterprises how to guard against and dissolve the PPP project risks related to [J]. Journal of new economy, 2016, (29).

[2] Du Yaling, Yin Yilin . The PPP project risk sharing research [J]. Journal of building economy, $2011(04)$

[3] Meng Chun, Guo Shang. To improve the PPP risk allocation mechanism [J]. Journal of development studies, 2016, (02).

[4] Gao Shenyuan, Cao Panpan, Yang Tao. Based on the PPP pattern of project operation risk research [J]. Value engineering, 2016, (26).

[5] Zhang Jie. System of PPP project risk - the "bird's nest" project, for example [J]. Journal of international engineering and services, 2014, (6). 